\title{
Web Supported Group Learning
}

\author{
I. T. Hawryszkiewycz \\ University of Technology, Sydney, Australia \\ igorh@it.uts.edu.au
}

\begin{abstract}
The paper describes ways to provide web based support for group learning especially in large subjects involving many groups. It begins by describing support tools that enable groups to carry out case studies. It distinguishes between different levels of support services ranging from group management systems, through support for informal exchange of information to proactive agent support systems that facilitate knowledge construction processes. It then outlines some experiences in the use of the system.
\end{abstract}

Keywords: Learning process, group learning, workspaces, software agents

\section{Introduction}

It is generally agreed that group learning is an effective way of acquiring knowledge. Working in groups both increases the breadth of knowledge acquired, its relevance, as well as evaluations of the application of new knowledge in a problem area. Group activities, however, are only effective if they follow processes that encourage idea generation and evaluation, discussion and conflict resolution in timely ways following well defined learning steps. This will enable students with different backgrounds (Biggs, 2000) to build on their knowledge through a continuous and guided process of identifying learning goals, discussing and trying ideas and recording outcomes in their learning outputs. The goal of the research described here is to facilitate ways in which students can benefit from group experiences, both in managing group activities and also ways develop knowledge in a particular subject area. The paper uses the idea of service (Hiltz \& Turoff, 2002) to describe support provided for learners in groups.

Most web-based support has emphasized individual learning in virtual classrooms (Wade \& Power, 1998). Group learning based on this support assumed that students could use the communication facilities provided with web based learning to themselves organize the complex process involved in group work. This paper suggests that services specific to group work are needed for the web to provide value added experiences to group work. Such services provide ways to manage groups as well as assisting the learning process. Support should go beyond the instructivist approach of carrying out teacher directed steps but provide ways to support constructivism and self-directed work, where students build on knowledge through organizing their work activities.

Material published as part of this journal, either on-line or in print, is copyrighted by Informing Science. Permission to make digital or paper copy of part or all of these works for personal or classroom use is granted without fee provided that the copies are not made or distributed for profit or commercial advantage AND that copies 1) bear this notice in full and 2) give the full citation on the first page. It is permissible to abstract these works so long as credit is given. To copy in all other cases or to republish or to post on a server or to redistribute to lists requires specific permission from the publisher at Publisher@InformingScience.org

\section{Levels of Support}

The paper distinguishes between three levels of support. Each of the levels assumes that a group workspace is created and services are provided through that workspace. The paper distinguishes between three levels of 
service, illustrated in Figure 1. These are:

- Level 1 services for group management that are usually provided through workspaces that facilitate group collaboration and maintain an up to date context for the group,

- Level 2 services that support informal knowledge sharing, and

- Level 3 services for learning, which provide ways to facilitate learning processes that lead to knowledge construction.

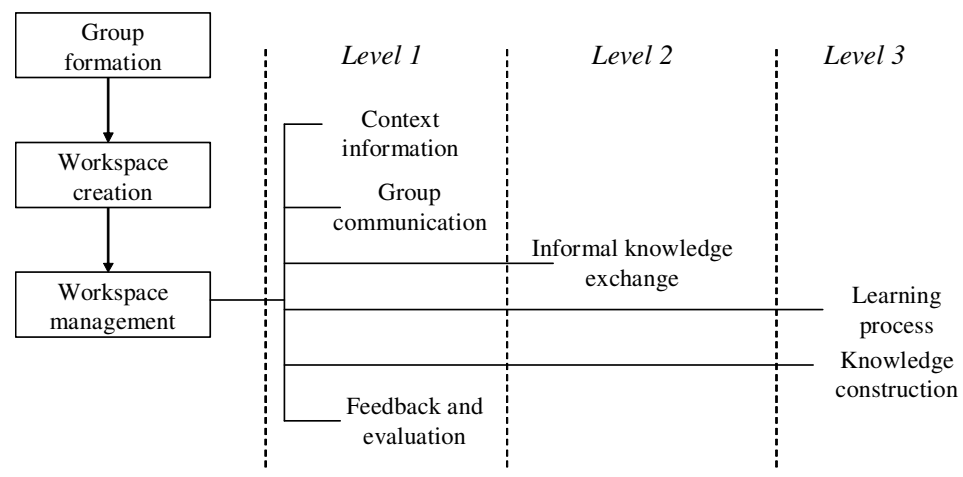

Figure 1 - Services for group management

There are also some common requirements for these levels. These are that any support system must be:

- learner driven and be adaptable to changing learning needs,

- presented within the learning context,

- allow gradual introduction to the use of technology.

The paper will first describe level 1 services to support group management and describe some experiences in their use. It then outlines some level 2 services and describes a prototype development whose goal is to provide level 3 services.

\section{Level 1 - Supporting Group Management}

Level 1 services include:

- Ability to form groups and establish spaces for these groups. Ability to customize workspaces that suit your group. Creation by the groups themselves provides a feeling of ownership as well as adapting the workspace to their particular work practices.

- Workspace management in the sense that the workspace can grow as students activities increase. The management should include developing workspaces that place student work in context.

- Provide ways to manage information about the current subject, case study as well as including records of knowledge construction and evaluation and feedback.

- The workspace arrangement should provide ways to structure information and abilities to assign responsibilities to selected students 


\section{Providing Group Management Services}

As an illustration we have used a system to support group management services. The system known as LiveNet (http://livenet4.it.uts.edu.au) has been developed within the Faculty of Information Technology. The system was introduced gradually to students following a process similar to that of Salmon (2000). Thus initially students use the system to access lecture material and engage in simple discussions to familiarize themselves with the system and ways of managing information repositories. This was primarily used with large classes of students learning about ebusiness and supported three kinds of activities (Hawryszkiewycz, 2002) namely a group case study, learning about particular technical topics, and presenting an individual topic critique. The system interface for the subject is shown in Figure 2, which is the latest version, version 4, of LiveNet, although most of the work reported here was carried out with an earlier version, which provides similar services.

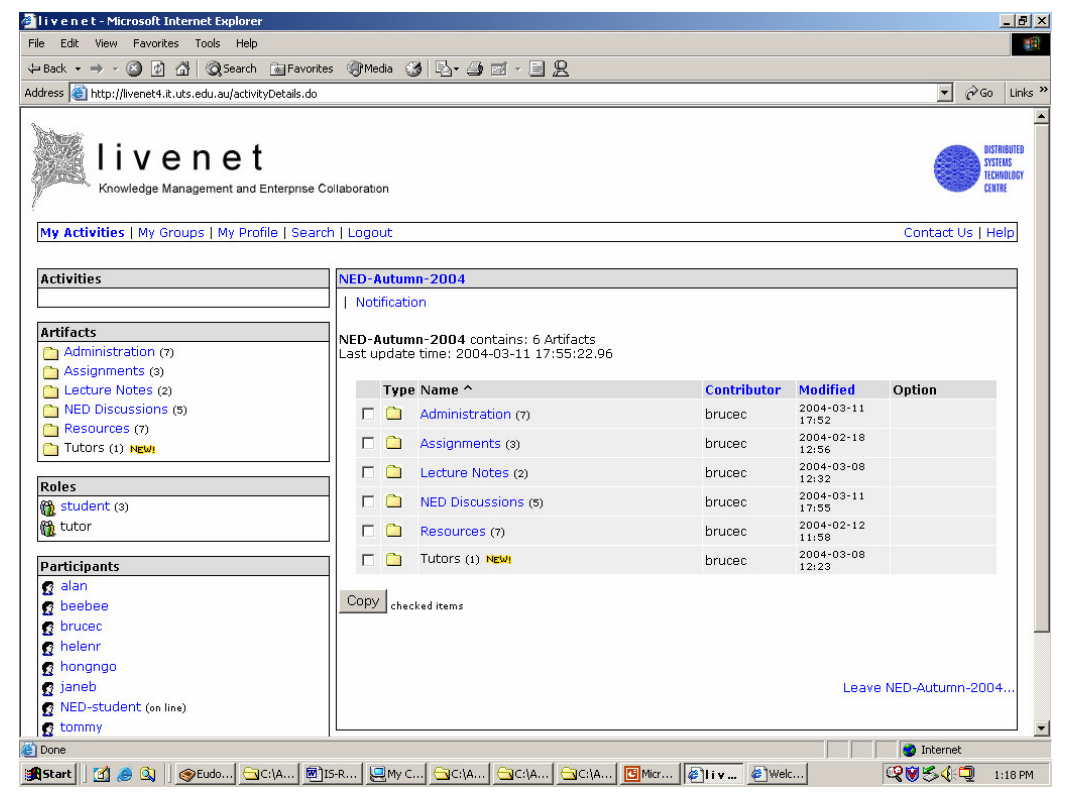

Figure 2 - A LiveNet collaborative services interface as seen by students

The workspace supported by LiveNet provides the ability to create any number of workspaces. Each workspace supports a different activity. Within a workspace it is possible to create any number of folders, or views, to store documents. It also allows group members to create any number of different roles with different abilities to access the views and change information within the views. Thus for example it is possible to create a folder named 'information-to-tutors' can only be seen by tutors thus reducing the need for meetings and saving peoples time. The interface can then be used to enter different learning activities to enter the body of knowledge and use its associated knowledge services. It can also enter any number of artifacts into a workspace. These range from files, through discussions and chatrooms, to plans, calendars and workflow events.

The interface also provides a way for students to form their own groups. They can simply select MyActivities and setup a new activity which is their own private space. One student enters the workspace creation option and in effect becomes the owner of the workspace. The owner can then invite other students into the workspace. They can then add any number of folders and assign roles to each other to reflect their work in the activity. 


\section{Some Experiences}

One goal of this subject was to teach students how to setup workspaces, which were then used to follow a design process to design systems. The students used their project workspace to carry out the design and then implement the design. In the case study students were given a sequence of milestones to aim for, starting with analysis, through design specification to setting up a prototype LiveNet system. Students were required to use their own project workspace to maintain the design documents as well as to use the workspace for their communication.

Generally, these were successful in the sense that students understood the basic LiveNet modeling method and workspace description and set up prototypes. The social effect of this is to require students to pace their work according to the process rather, as is often the case, leaving it to the last minute. This has an obvious learning benefit although it is perceived as a nuisance by some students because it requires them to follow a design process.

Lessons learned included design of workspaces to provide focused effort without the need of excessive navigation. Such focus is provided with our folders that focus on particular learning activities.

We experimented with different organizations of the subject context space. Our earlier workspaces provided separate spaces for tutor assistance, cases studies and overhead and administrative matters. The subsequent navigation led to some dissatisfaction and the creation of the workspace shown in Figure 2 is proving to be much more acceptable. This provides access to all these services but governance features and folders allow us to focus information for particular roles

In general workspaces were used mainly as a repository of design outcomes that could be shared by students at different locations. The discourse supported mainly concerned simple discussion databases or e-mail and was sparingly used by most groups. The learning process itself, including role assignment task definitions were generally made in face to face meetings and not recorded in the workspaces.

\section{Level 2 - Informal Knowledge Sharing}

Level 2 extends the level 1 services by:

- Allowing exchange information about artifacts developed as part of the group work,

- Relating the knowledge exchange within the context of the artifacts,

Experience here has shown that especially in situations where there is the possibility of face to face meetings, there is little exchange of information at this level. It is generally felt that unless this is facilitated very little use is made of these services for knowledge creation and they are mainly used to clarify subject assessment and management issues. They are also used to ask specific technical questions especially where there is some ambiguity in a particular term. Different instructors organize such discussions in different ways. Some are organized by topic, others by time and still others by current activities such as questions on exams. Similarly use of discussions in student workspaces is in most cases limited to questions regarding the progress of work.

Our current research now centers on ways to facilitate knowledge creation. The approach is to define the learning process and support it with agents, which facilitate the interaction needed to construct new knowledge. 


\section{Level 3 - Applying to Support Group Learning Processes}

The ultimate objective of the research is to evaluate whether finer definitions of group projects and assignments together with computer services can lead to better learning outcomes through computer assisted guidance of student groups. To outline objectives in more detail it is probably worthwhile to describe a typical scenario, which consists of the following steps:

Services here are provided to support and facilitate group dynamics themselves. These are summarized in Figure 3. They include the activities followed by students such as:

Formation of groups with common interests and availabilities,

Developing learning plans,

Assessing situations to determine what to do,

Role determination and allocation to accomplish work plans,

Resolution of conflicts in determining work plans, and

Recording of constructed knowledge, which can include reports produced by students, or design documents. It can also include intermediate discussions, or results that led to the final outcome.

An important aspect here is the recording of knowledge and assignment of work, associated with explicit recording in plans and a system to monitor and coordinate the work. These support services must exist in the workspace so that any records can be associated with the work context. The kinds of services proposed are illustrated in Figure 3.

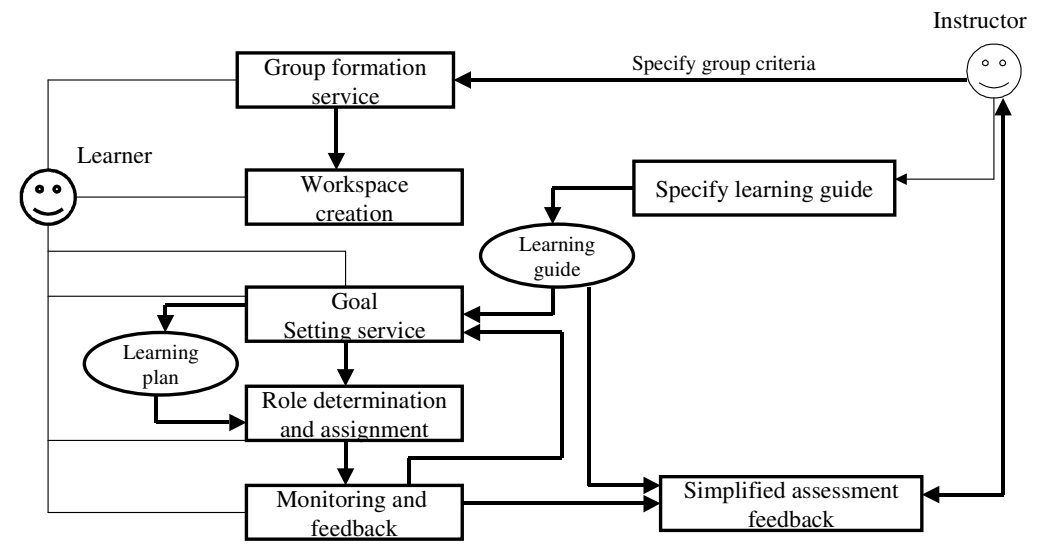

Figure 3 - Group Support Processes

A typical scenario here may go through the following steps:

\section{Step 1- facilitating group formation}

A teacher in design sets a case study that has a broad goal. The teacher first initiates a group formation service, which assists students to find group partners. It will provide an option to generate an initial workspace for group based on standard template. Alternatively the students can create their own group. An earlier version of this service was trialed in an earlier version of LiveNet. 


\section{Step 2: Facilitate the development of group learning plans.}

The teacher then proposes a group learning plan that defines the sub-goals for potential learning steps of a learning plan. This can be a guide of the steps to follow to design software, an engineering design or a business plan. The proposed system will also include suggestions for students to formulate their own learning plan.

\section{Step 3: Facilitated development of individual learning plans}

The learning plan can be progressively changed as group work proceeds. The learning plan will includes intermediate outputs (as is the case in practice), which may be evaluated, with teacher assistance, to ensure the plan is on track. It will include role assignments and responsibilities for components of the study. These can be adjusted as the study proceeds. This may be requirements analysis, followed by design, and implementation.

\section{Step 4: Monitoring group activities and providing feedback}

The system monitors progress and reports to the teacher significant potential problems indicated by lack of activity. The system provides a summary report that corresponds to the sub-goals of the learning guide that can be used for feedback using a simplified feedback screen. The system will also include the collection of usage activities for assessment.

One point to note in this approach is that discourses now become more complex. Whereas discourses in group management mainly concern simple exchanges and notifications, now the discussion can be more intense.

As a result of these experiences we are developing a more flexible architecture to support greater personalization. For this reason we are about to commence experimentation of a more flexible interface. We have also extended our system into a more flexible architecture and to include software agent support for the more complex discourses.

\section{Developing Learning Plans}

Figure 4 shows the basic features being developed to support learning in groups. The learning plan contains:

- A set of learning tasks,

- A set of guidelines, background and solution templates, and

- Start and end dates for each task.

The system then provides ways to extend it with agents that proactively support the group process shown in Figure 3. Our goal is to develop proactive agent systems (Hawryszkiewycz \& Lin, 2003), which will suggest activities to students, assist and guide them to setup the necessary discourse, and monitor group progress. The agents differ from those described in earlier work (Baylor \& Kim, 2003), which basically carried out task associated with a role, such as expert. Our agents are more process facilitators, whose goal is to support a learning process (Bransford, Brown, Cocking, 1999). Its goal is to ensure that students are aware of the learning tasks, where they can get assistance, and how they can best contribute to the group. 


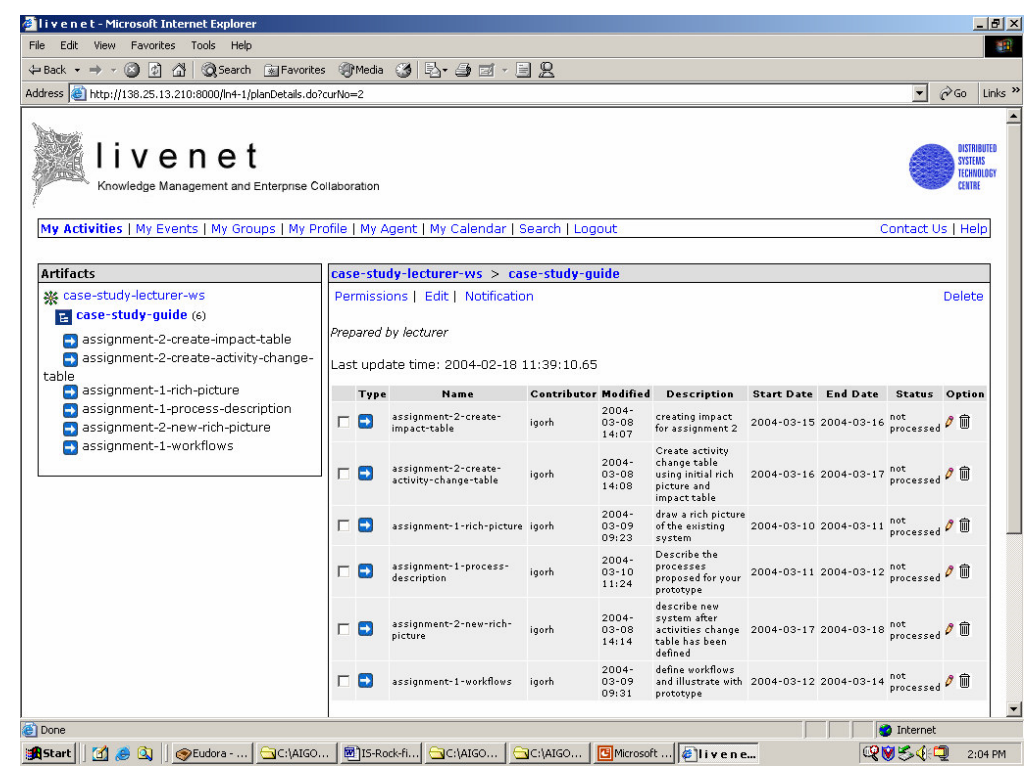

Figure 4 - Group study plan

The support system emphasizes a competency driven approach (Hezemans \& Ritzen, 2002) where each activity develops a new competency. Agents in the proposed system will set up special workspaces for each learning task and support each such workspace with messages and suggestions for activities that lead to student interactions and knowledge construction. An example of such workspace is shown in Figure 5.

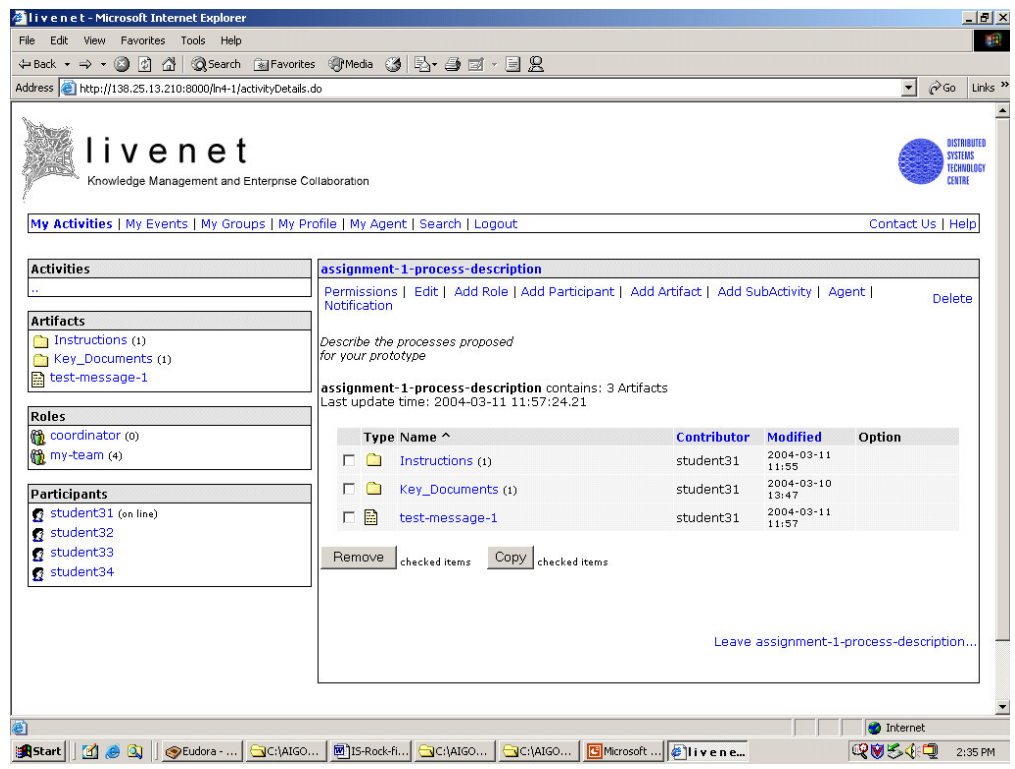

Figure 5 - Agent created workspaces

Figure 5 includes instructions for the learning task, a solutions template and associated discussion systems. The issues here are ways to specify good group learning processes and for agents to form opinions of how groups are proceeding and ways to suggest improvements that lead to good practices. Examples of services to be provided are: 
Goal setting where students analyze the current plan in light of their current outcomes and decide on the next step. The service will automatically gather all relevant information into the one workspace, and provide ways to adjust the learning plan, notifying all interested participants.

Role determination and assignment - assign tasks to individuals by role rotation for newly defined subgoals. This will introduce transparency into team member contributions.

\section{Summary}

The paper defined a framework for defining services needed to support student groups. It suggested a flexible approach to customizing learning spaces to a learner need. Three levels of service were defined, commencing with group management, then followed by informal information exchanges, and finally support for knowledge construction. The paper described experiences with the former two levels of service and described a prototype developed to support knowledge construction.

\section{References}

Baylor, A., \& Kim, Y. (2003). Validating pedagogical agent roles: Expert, motivator, and mentor. EDMedia 2003, $15^{\text {th }}$. Annual Conference on Educational Multimedia, Hypermedia and Telecommunications, Hawaii, June 2003. 2003.

Biggs, J. (2000). Teaching for quality learning at university. Open University Press.

Bransford, J. D., Brown, A. L. \& Cocking, R. R. (1999). How people learn. Washington, DC: National Academy Press.

Hawryszkiewycz, I. T. (2002). Designing learning activities from learning objects. ASCILITE, Auckland, December, 2002.

Hawryszkiewycz, I. T. \& Lin, A. (2003). Process knowledge support for emergent processes. Proceedings of the Second IASTED International Conference on Information and Knowledge Management, Scottsdale, Arizona, November, 2003, pp. 83-87.

Hezemans, M. \& Ritzen, M. (2002). Learning environments: Three types of learning environment. TeleLearning: The Challenge for the Third Millennium, IFIP Congress, Montreal, August 2000, Kluwer Academic Publishers, Boston, pp. 185-192.

Hiltz, R. \& Turoff, M. (2002). What makes learning networks effective? Communications of the ACM, 45 (4), 56-59.

Salmon, G. (2000). E-Moderating: The key to teaching and learning online. Sterling, VA: Stylus Publishing.

Wade, V. P. \& Power, C. (1998). Evaluating the design and delivery of WWW based educational environments and courseware. Proceedings of the $6^{\text {th }}$. Annual Conference on the Teaching of Computing, August 1998, Ireland, pp, 243-248.

\section{Biography}

Igor Hawryszkiewycz is Professor of Computing Science at the University of Technology Sydney, where his research and teaching interests are in collaborative systems and their application in business processes. He has been developing a collaborative system based on a generic metamodel, combining it with agents and applying in e-learning. His earlier work was in the area of database systems and system development methodologies, an area where he has a number of books and publications. 